\title{
Application of a novel a core-shell microstructured nanocomposites as a fire extinguishant using seawater
}

\author{
Liu Hao ${ }^{1}$, Zhang Tianwei ${ }^{1,2^{*}}$, Zhang Cunwei ${ }^{1,2}$, Xiao Lei ${ }^{1,2}$, Liang Qiang ${ }^{1}$ \\ ${ }^{1}$ China People's Police University, School of Rescue and Command, 065000 Langfang, China \\ ${ }^{2}$ China People's Police University, National Engineering Laboratory for Fire and Emergency Rescue, 065000 Langfang, China
}

\begin{abstract}
Water has unsurpassed capabilities in fire extinguishing. However, water scarcity is rapidly increasing in many regions and water shortage problems have led to find either new water resources or improve seawater treatment technologies. In this study, a new environment-friendly and high-efficiency powdered fire extinguishing agent with a core-shell structure is designed. The designed extinguishing agent is a colloidal powder with a $92 \%$ liquid content and is prepared through physical modification and high-speed shearing. Fumed silica is used for the external shell due to its chemical inertness, whereas seawater is used as the core due to its high extinguishing efficiency. Results show that the size of the prepared agent ranged between $100-200 \mu \mathrm{m}$. The two fire extinguishing experiments of different scales demonstrate that the employing inorganic salts with seawater as the core can significantly increase the efficiency of the new powder in extinguishing gasoline and diesel fire compared with ultrafine and common ABC dry powders. The suppression mechanism of action is caused by the combined flame chemical and pyrolysis theories of the potassium compounds. This study would be of great theoretical significance and application value for improving the application scope of the seawater.
\end{abstract}

\section{Introduction}

Petroleum and petroleum products, especially gasoline and diesel oil, are widely used in various applications in daily life[1]. Different types of finished gasoline and diesel products, which are highly combustible, can be stored in oil tanks[2]. However, casualties and property losses could arise should an oil tank combust and explode. Furthermore, oil tank combustion generates abundant thermal radiation, which hinders close-distance extinguishment[3]. The fire can affect adjacent oil tanks and cause a domino effect that will expand the reach of the accident and intensify the damage[4].

In fire outbreaks caused by oil tank combustion, traditional extinguishing methods apply water to cool the tank walls. When the temperature of the oil products have declined to a certain point, fire-extinguishing foam is applied to cover the burning liquid's surface until the fire is fully extinguished[5]. However, if the flame and tank wall temperature is $1050-1400{ }^{\circ} \mathrm{C}$ and $>1000{ }^{\circ} \mathrm{C}$, respectively, during the oil tank fire disaster, increased water will be needed to cool down the tank wall due to thermal radiation. These factors determine the amount of water and time that will be consumed before the oil surface sufficiently cools for foam application. These conditions cause water pollution and influence the firefighting opportunity. Moreover, vapors resulting from the contact between the hot oil surface and water can push the upper oil products out of the tank, causing boiling over and spraying. This occurrence may cause secondary damages[2]. In contrast, foams evaporate and disappear upon contact with the combusting liquid surface. After extinguishment, a thick foam layer is maintained on the oil surface to prevent after-combustions. Hence, a considerable amount of foam is needed to completely extinguish an oil tank fire. The toxic substances generated from the heating of the foam can damage the atmosphere to a certain extent. In brief, developing an environmentfriendly, clean, and highly efficient fire extinguishing agent for oil tank fires is necessary and urgent.

Compared with water and foam, dry powder extinguishing agents cover and extinguish fire through chemical reactions and can be applied onto the center of the fire without the need for special nozzles. However, dry powder has no cooling effect and has poor mobility and these properties limit its applications[6]. The new powder extinguishing agent with a core-shell structure combines the coverage capacity of the dry powder and the cooling effect of water and was prepared through high-speed shearing method. The core-shell particle(CSP) can successfully extinguish oil tank fire accidents and has advantages over the traditional extinguishing agents.

The designed extinguishing agent used hydrophobic particles for the shell and contained chemical extinguishing components comprising large amounts of water and some white powder[7]. Chen[8] developed a dry water extinguishing agent that used hydrophobic $\mathrm{SiO}_{2}$ for the shell and $\mathrm{NaCl}$ solution as the core. The core water content was $>60 \%$ and the addition of poval and

*Corresponding author: zhangtianwei_119@outlook.com 
ammonium sulfate significantly improved the distribution of the particle size. This dry water extinguishing agent was superior to the commercial $\mathrm{ABC}$ and $\mathrm{BC}$ dry powders in terms of octane fire extinguishing efficiency. Ni[7] developed an extinguishing agent that employed hydrophobic $\mathrm{SiO}_{2}$ for the shell and distilled water as the core and used it against gasoline fire. This agent developed a synergistic effect during extinguishment and was significantly superior to $\mathrm{SiO}_{2}$ or water. Furthermore, the same extinguishing agent, which had been stored for one year, was used in the comparison experiment. The extinguishing efficiency remained the same and demonstrated good storage performance of the powder. Han[9] studied a dry water extinguishing agent that employed hydrophobic $\mathrm{SiO}_{2}$ for the shell and phosphoric acid solution as the core and found that the acid solution can exist as a stable core. Moreover, he improved the traditional spraying device; hence, significantly saving extinguishing agents from spraying loss.

In the aforementioned studies on dry powder extinguishing agents, $\mathrm{SiO}_{2}$ particles were used in the production of rigid droplet-shaped shells and the extinguishing components served as the core. The studies mainly focused on the physical and chemical properties of the extinguishing agents. The agents' uniqueness and efficiency in extinguishing gasoline or diesel oil fire were noted. Further studies are still needed to elucidate the materials' structural strength. Zhang[10] discovered that dissolving some potassium compounds into water can increase the chemical extinguishing efficiency of pure water. Moreover, appropriate proportions of potassium compounds can react with Gellan gum to form a gel that possesses structural strength and high elasticity. These materials can increase the strength of the core-shell structure.

In this paper, a powder extinguishing agent with a gel core-shell structure was prepared using $\mathrm{SiO}_{2}$ for the shell and seawater as the core through high-speed shearing method. This extinguishing agent was added with Gellan gum and methyl hydrogen silicone oil to increase its structural strength. The preparation technique, morphology, pressure resistance, and extinguishing efficiency against gasoline and diesel oil fire of the retardant were studied. The extinguishing mechanism was discussed based on theory and experimental results.

\section{Experimental Method}

\subsection{Sample Preparation and Characterization}

The raw materials, including fumed $\mathrm{SiO}_{2}$, the inorganic salts prepared for artificial seawater, Gellan gum, and methyl hydrogen silicone oil were purchased from Aladdin ${ }^{\circledR}$ and required no further purification. The powder extinguishing agent was prepared using a 966B homogenizer. The power, rotating speed range, and volume of the homogenizer were $800 \mathrm{~W}, 10000-30000$ $\mathrm{r} / \mathrm{min}$, and $2.0 \mathrm{~L}$, respectively.

The method of seawater configuration was as follows: $25 \mathrm{~g}$ sodium chloride $(\mathrm{NaCl}), 11 \mathrm{~g}$ magnesium chloride hexahydrate $\left(\mathrm{MgCl}_{2} \cdot 6 \mathrm{H}_{2} \mathrm{O}\right), 1.6 \mathrm{~g}$ calcium chloride dihydrate $\left(\mathrm{CaCl}_{2} \cdot 2 \mathrm{H}_{2} \mathrm{O}\right)$ and $4 \mathrm{~g}$ sodium sulphate $\left(\mathrm{Na}_{2} \mathrm{SO}_{4}\right)$ were separately dissolved in $1 \mathrm{~L}$ distilled water $(<$ $0.06 \mu \mathrm{S} / \mathrm{cm})$.

A certain quantity of hydrophobic $\mathrm{SiO}_{2}$, seawater, Gellan gum, and methyl hydrogen silicone oil were weighed on electronic scales. Gellan gum was added to the boiling pure water and mixed evenly through stirring. Next, the mixture was poured into the stirring container of the homogenizer and certain amounts of $\mathrm{SiO}_{2}$, inorganic salts required in seawater and methyl hydrogen silicone oil were added and blended continuously for $30 \mathrm{~s}$ at a rate of $17000 \mathrm{r} / \mathrm{min}$. The final products were left to cool at room temperature. After the temperature cooled to $30^{\circ} \mathrm{C}$ to $45^{\circ} \mathrm{C}$ the powder extinguishing agent with a gel-type core-shell structure was prepared.

Morphology of the prepared extinguishing agent was observed under a PH50-3A43L-EP/PL ternary TV optical microscope with the total magnification power of the microscope was $1600 \times$, the microscope of which was equipped with objective lens with four different magnification powers $(4,10,40$, and $100 \times)$.

\subsection{Fire Extinguishing Tests}

Many methods exist for testing extinguishing efficiency, such as cup-burner, micro-nozzle, chemical analysis, portable fire extinguisher, and pressure tank spraying methods. Each method has its advantages, disadvantages, and specific application. The fire model, which is used in the portable fire extinguisher and pressure tank spraying method, resembles actual fire accidents. These methods are applied by many international standards to test the extinguishing efficiency of condensed-phase extinguishing agents. However, international standard experiments cover a large scale and require considerable manpower and materials. Therefore, our laboratory study assessed the extinguishing efficiency of the prepared retardant on a reduced scale according to the GA499.12010, GB 4066.2-2004, and GB50898-2013 designs[1113].

The small-scale extinguishing experiment was carried out in a limited space of $1 \mathrm{~m}^{3}(1.2 \mathrm{~m} \times 0.7 \mathrm{~m} \times 1.2 \mathrm{~m})$. In the experiment, a portable $0.5 \mathrm{~kg}$ extinguisher was used. The inner diameter and the cone angle of the nozzle were $1.8 \mathrm{~mm}$ and $60^{\circ}$, respectively. To address the effects of empirical factors on the portable fire extinguisher, we placed a nozzle with an external steel tube at the spraying entrance. The spray angle was limited to $0^{\circ}-5^{\circ}$ to decrease effects of operational variability on the experimental results. The experimental set-up is shown in Fig. 1a.

The spray entrance was located $91 \mathrm{~cm}$ from the fire source and the nozzle was $110 \mathrm{~cm}$ above the ground. In the experiment, a $20 \mathrm{~cm} \times 20 \mathrm{~cm} \times 5 \mathrm{~cm}$ square oil pan was used. Four pieces of K-type nichrome alloy thermocouple were employed to measure the temperature at different heights of the flame at $10 \mathrm{~cm}$ intervals. The bottom thermocouple was $6 \mathrm{~cm}$ above the bottom of the oil pan. The experiment consumed $200 \mathrm{~mL}$ of gasoline and diesel fuels. Before the experiment, the net weight of the extinguisher cylinder $\left(\mathrm{M}_{1}\right)$ was measured and a certain amount $\left(\mathrm{M}_{2}\right)$ of the prepared extinguishing agent was 
loaded into the extinguisher. The tank was filled with nitrogen at $1 \mathrm{MPa}$ filling pressure. At the beginning of experiment, the gasoline in the oil pan was ignited and preburned for $30 \mathrm{~s}$ under uncovered conditions. The box gate was closed after the flame has stabilized and the extinguishing agent was sprayed. The time from spraying to extinguishing was noted with a mechanical stopwatch. Application of the extinguishing agent was stopped after the flame was fully extinguished. The weight of the extinguisher $\left(\mathrm{M}_{3}\right)$ was measured, and the actual consumption of the extinguishing agent was calculated.
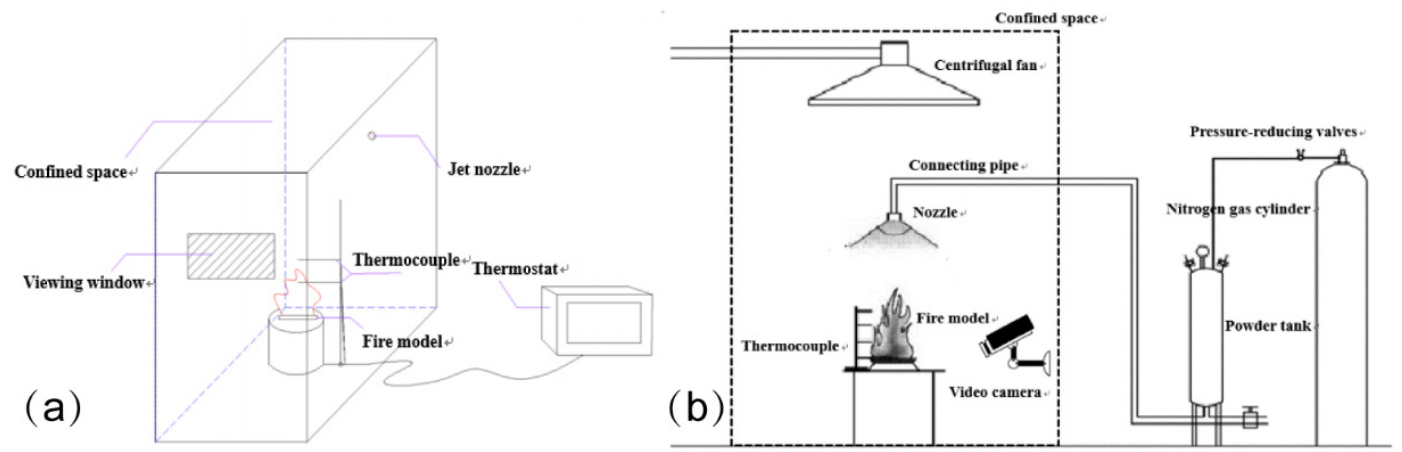
with a digital camera. up is shown in Fig. 1b.

Fig1. Diagrammatic sketch of the fire extinguishing test (a) small-scale and (b) medium-scale.

The nozzle was installed $150 \mathrm{~cm}$ above the bottom of the oil pan. In the experiment, the diameter and height of the oil pan were $50 \mathrm{~cm}$ and $10 \mathrm{~cm}$, respectively. Four Ktype nichrome alloy thermocouples were installed at 20 $\mathrm{cm}$ intervals. The bottom thermocouple was placed $3 \mathrm{~cm}$ below the oil surface. The experiment consumed $500 \mathrm{~mL}$ of gasoline and diesel fuels. The bottom of the oil pan was $15 \mathrm{~cm}$ above from the ground. The oil pan's diameter and height were 50 and $10 \mathrm{~cm}$, respectively, and was set for pre-burning. The pan was filled with $200 \mathrm{~mL} \mathrm{n}$-heptane to ignite the diesel. Before the experiment, the net weight of the extinguisher cylinder $\left(\mathrm{M}_{1}\right)$ was measured. A certain amount $\left(\mathrm{M}_{2}\right)$ of the prepared extinguishing agent was loaded into the tank, which was then filled with nitrogen at $1 \mathrm{MPa}$. The gasoline or $\mathrm{n}$-heptane was ignited and the fireproof door was closed. The timing was simultaneously started with the ignition of the gasoline or diesel. The extinguishing agent was applied after $30 \mathrm{~s}$, and the application was stopped immediately after the flame was extinguished. The time from spraying to extinguishment was noted with a mechanical stopwatch. The weight of the extinguisher $\left(\mathrm{M}_{3}\right)$ was measured and the actual consumption of the extinguishing agent was calculated. Considering the uncertainty in the timing and the quality of the extinguishing experiment, the margin of error was set to $\pm 10 \%$.

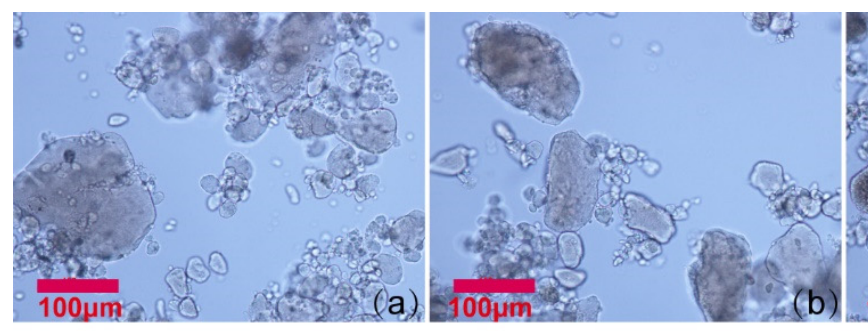

Each experiment was repeated for at least five times and the mean was calculated. The experiment was recorded

The medium-scale extinguishing experiment was carried out in a limited space of $27 \mathrm{~m}^{3}(3 \mathrm{~m} \times 3 \mathrm{~m} \times 3 \mathrm{~m})$. In this experiment, a $5 \mathrm{~kg}$ tank extinguisher was used and the nozzle was set at the exit of the powder transmission pipe. The inner diameter and the cone angle of the nozzle were $1.8 \mathrm{~mm}$ and $60^{\circ}$, respectively. The experimental set-

\section{Result and discussion}

\subsection{Sample Morphology}

According to previous experimental results, the water content of CSP could reach as high as $95 \%$. However, the overly high water content may cause adverse effects on moisture retention and structural strength. A comparison of the particle sizes of the powders which is prepared using different liquid/solid ratios (seawater/ $\mathrm{SiO}_{2}$ ratio) is shown in Fig.2.

The particle size gradually decreases with increasing liquid/solid ratio. Chen[8] concluded that the powder extinguishing agent achieved optimal mobility and performance at $100-300 \mu \mathrm{m}$. According to the particle size test results, the $100-300 \mu \mathrm{m}$ particles account for the highest proportion $(72.6 \%)$ in comparison with the other sizes at 92:8 liquid/solid ratio. Further increasing the $\mathrm{SiO}_{2}$ content (liquid/solid ratio $=91: 9$ ) results in the production of a considerable amount of non-enveloped powder, and the raw materials are not completely able to form a coreshell structure. As shown in Fig.2, all of the particles are spheres or spheroid. Particle size is positively related with the liquid/solid ratio which is minimal at 92:8 liquid/solid ratio with most particles range between $100-300 \mu \mathrm{m}$.

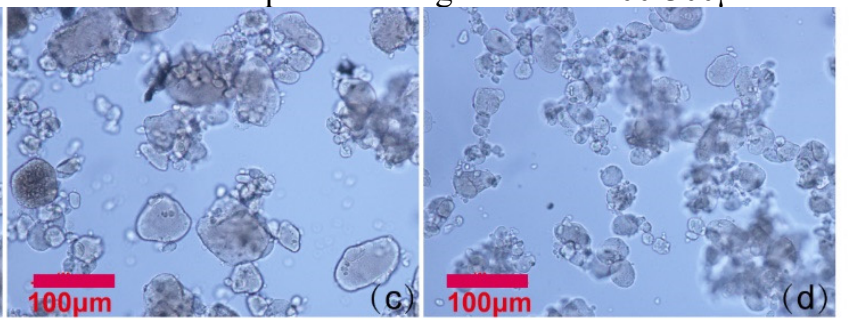

Fig2. Images of the particles morphology at different seawater/ $\mathrm{SiO}_{2}$ ratios: (a) 95:5, (b) 94:6, (c) 93:7, and (d) 92:8.

In this paper, the mass fractions of the Gellan gum and methyl hydrogen silicone oil are kept constant during the 
preparation. The Gellan gum could reduce the water loss and increase the internal structural strength and moisture retention of the agent. Methyl hydrogen silicone oil could enhance the resistance of powders to agglomeration and increase its mobility. Hence, adding a certain mass fraction of methyl hydrogen silicone oil could increase the adsorption capacity of the $\mathrm{SiO}_{2}$ solution and offset the influence of the extinguishing components and heating process on the surface tension of the liquid phase[9]. Gellan gum and silicone oil could also influence the surface tension of the liquid phase[14], and the relationship between the variation in mass fraction and types of the additives on the surface tension of the liquid

Table1. Suppression efficiency of the samples in extinguishing gasoline and diesel fires.

\begin{tabular}{|c|c|c|c|c|}
\hline Sample composition & Particle size $/ \mu \mathrm{m}$ & Fire model/size & Mass of consumed sample /g & Extinguishing time $/ \mathrm{s}$ \\
\hline $\begin{array}{c}\mathrm{CSP} \\
\left(8 w t \% \mathrm{SiO}_{2}+92 w t \% \text { water }\right)\end{array}$ & $100-300$ & Gasoline/Small & $54.8 / 48.3 / 52.1 / 49.6 / 55.7$ & $6.5 / 4.7 / 4.3 / 5.9 / 6.7$ \\
\hline $\begin{array}{c}\mathrm{CSP} \\
\left(8 w t \% \mathrm{SiO}_{2}+92 w t \% \text { seawater }\right)\end{array}$ & $100-300$ & Gasoline/Small & $24.6 / 21.9 / 23.9 / 22.6 / 24.4$ & $2.7 / 1.4 / 2.4 / 2.0 / 2.4$ \\
\hline $\begin{array}{l}\text { Ultrafine } \mathrm{ABC} \text { powder } \\
\left(>50 w t \% \mathrm{NH}_{4} \mathrm{H}_{2} \mathrm{PO}_{4}\right)\end{array}$ & $9.2-18.7$ & Gasoline/Small & $36.7 / 36.1 / 34.8 / 33.2 / 35.4$ & $3.4 / 4.8 / 5.2 / 3.8 / 4.7$ \\
\hline \multirow{2}{*}{$\begin{array}{c}\mathrm{CSP} \\
\left(8 w t \% \mathrm{SiO}_{2}+92 w t \% \text { seawater }\right)\end{array}$} & \multirow{2}{*}{$100-300$} & Gasoline/Medium & $145.4 / 168.2 / 155.3 / 147.7 / 168.7$ & $8.4 / 10.2 / 9.0 / 11.1 / 9.2$ \\
\hline & & Diesel/Medium & $111.5 / 82.7 / 100.9 / 113.4 / 95.6$ & 8.2/7.7/8.1/7.9/7.1 \\
\hline \multirow{2}{*}{$\begin{array}{c}\mathrm{CSP} \\
\left(8 w t \% \mathrm{SiO}_{2}+92 w t \% \text { water }\right)\end{array}$} & \multirow{2}{*}{$100-300$} & Gasoline/Medium & $153.7 / 166.4 / 175.5 / 169.2 / 188.2$ & $9.2 / 9.5 / 8.4 / 11.3 / 10.4$ \\
\hline & & Diesel/Medium & $122.1 / 117.8 / 113.5 / 120.8 / 107.4$ & 9.1/8.8/8.5/8.9/9.5 \\
\hline \multirow{2}{*}{$\begin{array}{l}\text { Commercial } \mathrm{ABC} \text { powder } \\
\left(>50 w t \% \mathrm{NH}_{4} \mathrm{H}_{2} \mathrm{PO}_{4}\right)\end{array}$} & \multirow{2}{*}{$90-150$} & Gasoline/Medium & $339.7 / 364.2 / 352.5 / 382.6 / 377.7$ & $12.0 / 12.4 / 14.1 /-/-$ \\
\hline & & Diesel/Medium & $280.4 / 254.2 / 268.9 / 310.5 / 277.4$ & $10.4 / 9.8 / 11.4 / 10.5 / 9.7$ \\
\hline
\end{tabular}

As shown in Table 1, the average consumption of the as-prepared samples is 23.48-39.8 $\mathrm{g}$ with the average extinguishing time is $2.18-5.08 \mathrm{~s}$. No re-burn is observed after the extinguishment. The extinguishing efficiency of as-prepared samples is equivalent to the ultrafine $\mathrm{ABC}$ dry powder $(35.24 \mathrm{~g}$ at $4.38 \mathrm{~s})$. The seawater-CSP shows the lowest consumption and the shortest extinguishing time
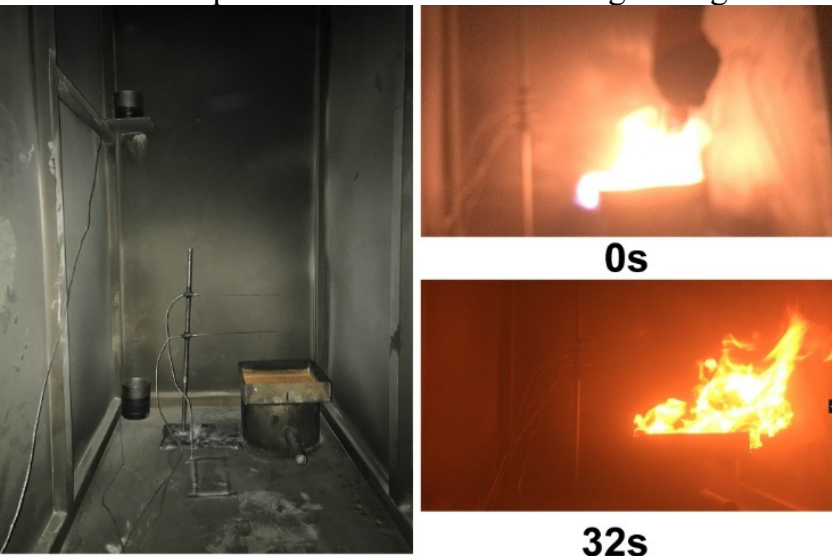

$32 s$ phase will be introduced in future studies

\subsection{Fire Extinguishing Efficiency}

In the extinguishing efficiency experiment, ultrafine and common $\mathrm{ABC}$ dry powders are used for comparison with the loading contents in the storage tank were 100 and 400 g, respectively. Experimental results of the two experimental scales are shown in Table 1, including the composition, particle size, amount consumed, and extinguishing time. among all the agents, which is $\sim 1.8$ times higher than the ultrafine $\mathrm{ABC}$ dry powder. The extinguishing efficiency of the powders that used solutions as the core is better than the powders that used pure water $(52.1 \mathrm{~g}$ at $5.62 \mathrm{~s})$. The extinguishing process in the small-scale experiment is shown in Fig.3.
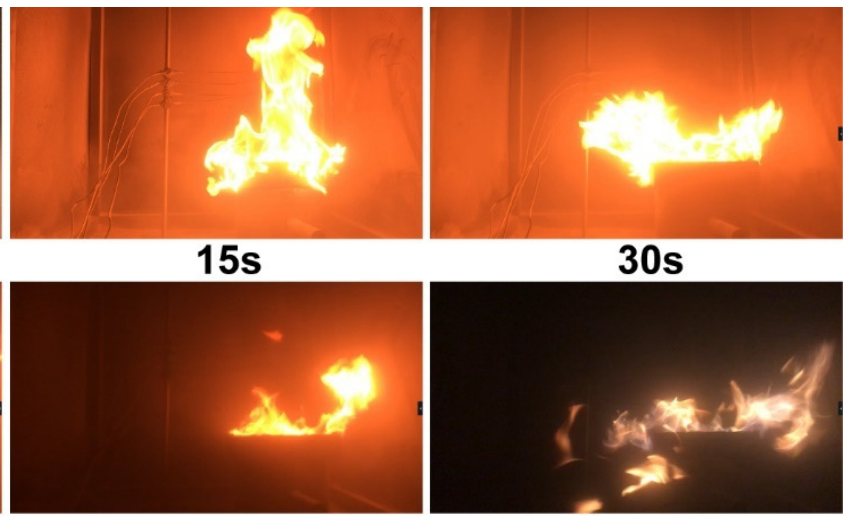

34s

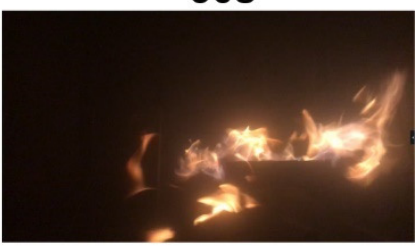

$36 s$

Fig3. Images of the fire extinguishing process in the small-scale test using seawater $/ \mathrm{SiO}_{2}$ particles.

As shown in Table 1, both seawater-CSP and waterCSP can extinguish gasoline and diesel fires in the medium-scale experiment, while an extinguishing failure is observed in the gasoline pool fire experiment using common ABC dry powder. The average consumption of the agents and the extinguishing times of seawater-CSP are $157.06 \mathrm{~g} / 9.58 \mathrm{~s}$ for gasoline fire and $100.82 \mathrm{~g} / 7.8 \mathrm{~s}$ for diesel fire, respectively. And for the water-CSP, the number of which are $170.61 \mathrm{~g} / 9.76 \mathrm{~s}$ and $116.32 \mathrm{~g} / 8.96 \mathrm{~s}$, respectively. The average consumption of commercial $\mathrm{ABC}$ powder in suppressing gasoline and diesel fires is
$363.34 \mathrm{~g}$ and $278.28 \mathrm{~g}$ with the extinguishing times of 12.83 and $10.36 \mathrm{~s}$, respectively. The results of which are significantly higher than that of seawater-CSP and waterCSP. Ni[7] noted that the extinguishing efficiency of water-CSP in the gasoline fire experiment was higher than the common $\mathrm{ABC}$ dry powder due to the particle size of water-CSP was $10-30 \mu \mathrm{m}$, which was lower than that of common ABC dry powder $(70-100 \mu \mathrm{m})$. The particle dispersion and specific surface area increases with the particle size decreases, which are conducive for the particle in the flame free radicals (FFRs) adsorption and 
strengthen the homogeneous phase inhibition by increasing the endothermic decomposition and reaction rate between the inorganic salts in the seawater and FFRs. On this basis, decreasing the particle size of the seawater-
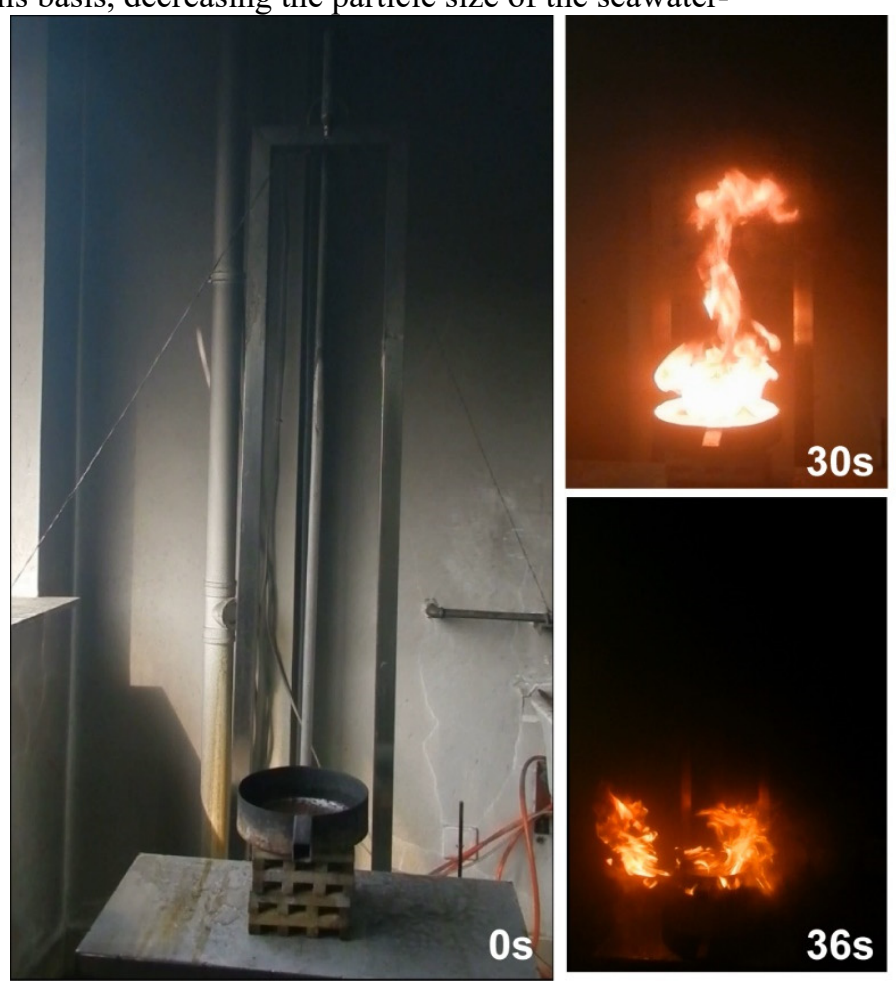
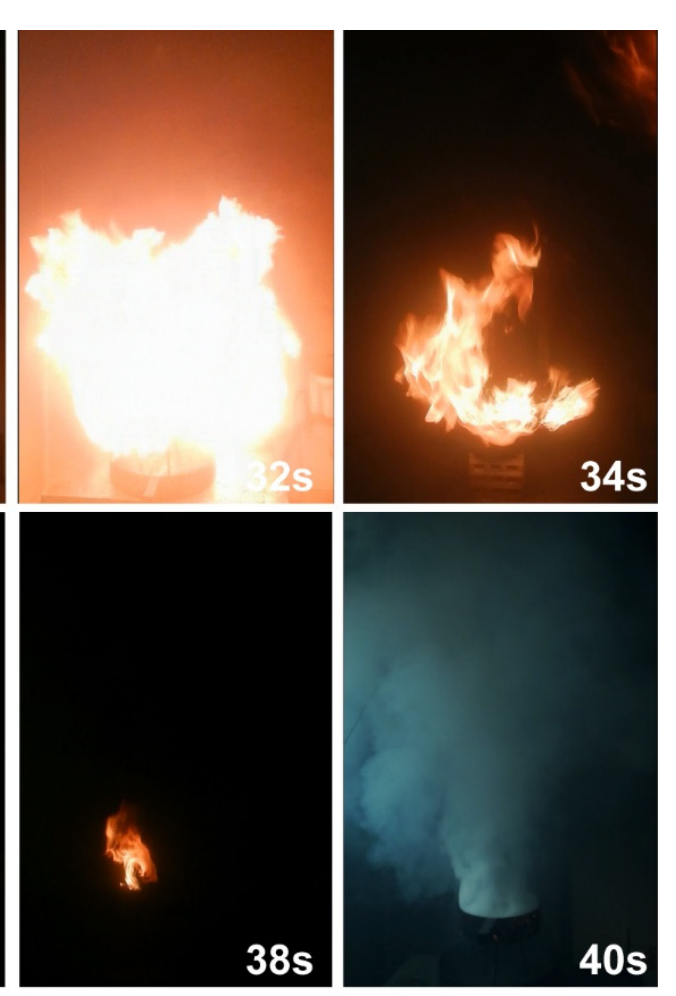

CSP might increase the extinguishing efficiency. The typical extinguishing process of the medium-scale experiment using seawater-CSP is shown in Fig. 4.

Fig4. Images of the gasoline pool fire extinguishing process in the medium-scale test using seawater-CSP.

\subsection{Fire Extinguishing Mechanism}

The homogeneous chemical effects of seawater-CSP in fire extinguishing is the elimination effects of gaseous active species on FFRs, which is the decomposition products of solutes under the flame temperature [15]. The species $\mathrm{Cl}$ which is produced by $\mathrm{NaCl}, \mathrm{MgCl}_{2} \cdot 6 \mathrm{H}_{2} \mathrm{O}$ and $\mathrm{CaCl}_{2} \cdot 2 \mathrm{H}_{2} \mathrm{O}$ of seawater under high temperature conditions could act as an inhibitor in promoting the conversion of $\mathrm{H}$ and $\mathrm{OH}$ to $\mathrm{H}_{2}$ and $\mathrm{H}_{2} \mathrm{O}$ through the reaction (1)-(4). The concentration of FFRs is reduced, which clearly influences the key chain reaction (i.e., (5)) of propane combustion, limiting the degree of chain reaction or catalyzing the chain termination process [16$18]$.

$$
\begin{aligned}
& \mathrm{Cl}+\mathrm{Cl}+\mathrm{M} \rightarrow \mathrm{Cl}_{2}+\mathrm{M} \\
& \mathrm{Cl}_{2}+\mathrm{H} \rightarrow \mathrm{HCl}+\mathrm{Cl} \\
& \mathrm{HCl}+\mathrm{H} \rightarrow \mathrm{H}_{2}+\mathrm{Cl} \\
& \mathrm{H}+\mathrm{OH}+\mathrm{Cl} \rightarrow \mathrm{H}_{2} \mathrm{O}+\mathrm{Cl} \\
& \mathrm{O}_{2}+\mathrm{H} \rightarrow \mathrm{OH}+\mathrm{O}
\end{aligned}
$$

The homogeneous chemical effects of Na-containing species in flame suppression is the FFR scavenging effects by gaseous decomposition products through the reaction (6)-(9), which promotes the transformation of $\mathrm{H}, \mathrm{O}$ and $\mathrm{OH}$ to a stable molecule [19-21]. 

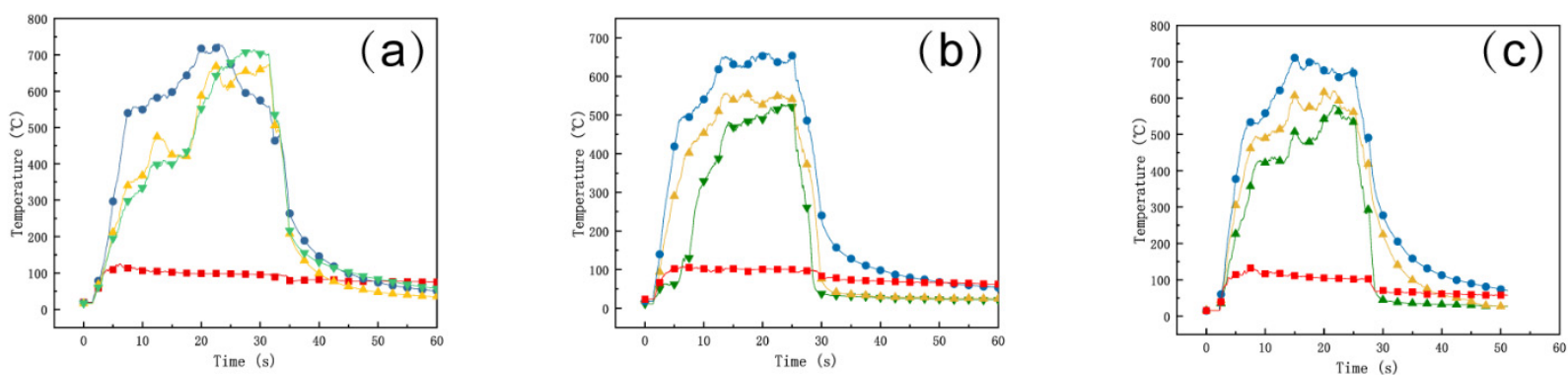

Fig5. Flame temperature in small-scale tests: (a) water-CSP, (b) seawater-CSP, (c)ultrafine ABC powder.

Based on the total flooding mechanism, the fire extinguished by ultrafine $\mathrm{ABC}$ powder is mainly depended on the physical and chemical interactions when powders and flames are mixed. The amount of FFRs are reduced by the recombination reactions with gaseous active substances generated by thermal decomposition, and the oxygen is isolated by a glassy-like cover layer formed on the surface of the combustion material. However, as seen from Table 1, little difference in fire extinguishing efficiency between seawater-CSP and ultrafine ABC powder, although the particle size of seawater-CSP is nearly 10 times than that of ultrafine $\mathrm{ABC}$ powder. This indicates that seawater-CSP has good suspension and high dispersion, the effect of endothermic cooling of inner liquid and dilution by seawater-CSP is equivalent to the gas-phase chemical inhibition of ultrafine $\mathrm{ABC}$ powder.

Temperature changes of the particles used in the

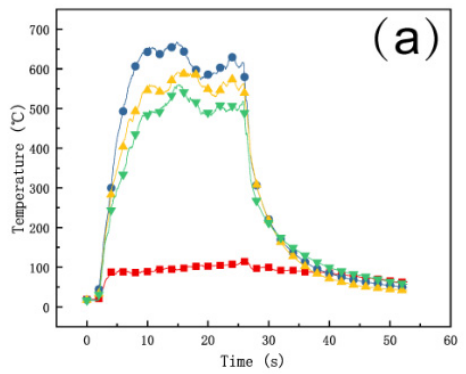

medium-scale experiment are shown in Fig. 6. However, the oxygen dilution is not the main extinguishing mechanism due to the adequate oxygen content in the medium-scale extinguishing tests. The extinguishment mechanism of seawater-CSP is the result of the combined effects of coverage, dilution, heat and thermal radiation absorption. More heat absorption by the phase change occurs in the flame under the protection of the heatresistant shell(i.e. $\mathrm{SiO}_{2}$ ), which could reduce the evaporation loss of the fine water droplets during the ejecting process. Reflected in the flame temperature, that is, the flame temperature drop rate under the action of seawater-CSP is fast, the re-ignition phenomenon occurs after the common ABC powder is completely applied due to the poor cooling effect, causing the flame temperature increasing.

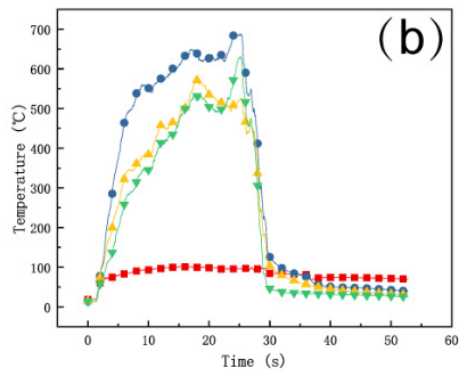

Fig6. Flame temperatures in the medium-scale tests: (a) seawater-CSP and (b) Common-ABC

The efficiency improvement of seawater-CSP relative to common $\mathrm{ABC}$ powder in the diesel fire is more significant than in the gasoline fire, as shown in Fig. 6, which is because of the diesel demonstrates a higher surface temperature $\left(\sim 300^{\circ} \mathrm{C}\right)$ compared to gasoline $(<$ $100^{\circ} \mathrm{C}$ ) during combustion. Liu[28] indicated that surface cooling was the main extinguishing mechanism in liquid fuels with low combustion surface temperature, and the extinguishment only occurs for burning liquid fuels with high temperatures under the synergistic effect of surface and flame cooling. The seawater-CSP has good suspension characteristics, and a heat-resistant shell which leads most of the heat absorption of water by phase change in diesel flames. Therefore, GDW has higher efficiency and is more suitable for extinguishing the fires with higher temperature of fuel surface during combustion, lower consumption and a shorter dousing time of the extinguishing agents is observed in diesel fire compared to that of gasoline fire.

\section{Conclusion}

Gasoline and diesel tanks have high risks for fire accidents Explosive combustion of gasoline and diesel tanks is a great threat to personnel safety and to the surrounding structures. Traditional extinguishing agents (e.g., water and dry powder) have limited effects on the extinguishment of gasoline or diesel fires. Therefore, a novel core-shell particle with inner seawater as a fire extinguishant is designed and developed, which can combine the advantages of the traditional extinguishing agents and offset their disadvantages, and several extinguishing mechanisms could be responsible for the extinguishing process.

At present, water resources are becoming increasingly strained due to the decrease of the total amount of water 
resources caused by the uncertainty of global climate change, and the application of seawater (accounting for $97.5 \%$ of global water resources) as the liquid core is one of the important researches and development aspects of CSP materials. The strong corrosion behavior on the storage and injection equipment is likely the main reason why seawater has not yet been applied in fire-fighting practice at the full scale, although the inorganic salts from seawater exhibit a certain chemical effect in the process of fire extinguishing. The physical barrier formed by nanoscale particles between seawater and equipment can exactly reduce the corrosion rate of metal theoretically, which makes the seawater has more potential than fresh water as liquid core of CSP materials for fire extinguishants.

\section{Acknowledgment}

Financial support by the National Natural Science Foundation of China (No. 51804314), Natural Science Foundation of Hebei (No. E2019507007), Key R\&D Program of Hebei Province(No. 20375503D) and Key Scientific Research Projects in China People's Police University (No. 2019zdgg006)

\section{References}

1. L. Kong, Y. Gao, Q. Zhou, Z. Sun. J.Hazard.Mater., 343(2017)

2. R.M. Leite, F. R. Centeno. J.Hazard.Mater., 342(2017)

3. X. Liu, L.Tong, H.Wang, Z. Zheng, M. Yao. Appl. Energ., 189(2017)

4. V. Suchá, M. Mihaljevič, V. Ettler, L. Stmad. J. Environ. Manage., 171(2016)

5. L. H. Hu, S. Liu, W. Peng, R. Huo. J.Hazard.Mater., 169(2009)

6. X. Ni, X. Wang, S. Zhang, M. Zhao. J. Fire Sci., 32(2014)

7. X. Ni, S. Zhang, Z. Zheng, X Wang. J.Hazard.Mater., 341(2017)

8. X. Chen, A. Fan, B. Yuan, Y. Sun, Y. Zhang. J. Loss Prevent Proc., 59(2019)

9. Z. Han, Y. Zhang, Z. Du, F. Xu, S. Li, J. Zhang. J. Clean. Prod. 166(2017)

10. T. Zhang, Z. Han, Z. Du, Z. Zhang, K. Liu. Int. J. Hydrogen Energ. 41(2016)

11. T. Zhang, Z. Han, Z. Du, K. Liu, Z. Zhang. Appl. Therm. Eng., 107(2016)

12. Y. Yan, Z. Du, Z. Han. Fire Mater., 43(2019)

13. T. Zhang, Z. Du, Z. Han, K. Liu. Appl. Therm. Eng., 102(2016)

14. T. Zhang, H. Liu, Z. Han, Z. Du. Appl. Therm. Eng., 122(2017)

15. V. Babushok, W. Tsang, G. T. Linteris, D. Reinelt. Combust. Flame., 115(1998)

16. R. Zheng, K. N. C. Bray, B. Rogg. Combust Sci. Technol., 126(1997)

17. X. Cao, J. Ren, Y. Zhou, Q. Wang, X. Gao, M. Bi.
J.Hazard.Mater., 285(2015)

18. W. E. Wilson, J. T. O'donovan, R. M. Fristrom. Symposium (International) on Combustion, 12(1969)

19. . A. J. Hynes, M. Steinberg, K. Schofield. J. Chem. Phys., 80(1984)

20. B. A. Williams, J. W. Fleming. HOTWC, 4(1999)

21. O. Dounia, O. Vermorel, T. Poinsot. Combust. Flame., 193(2018)

22. Y. Koshiba, T. Haga, H. Ohtani. Fire Safety J., 109(2019)

23. D. H. Cotton, D. R. Jenkins. Trans. Faraday Society, 67(1971)

24. A. Hamins. Symposium (International) on Combustion, 27(1998)

25. Jr. W. A. Rosser, S. H. Inami, H. Wise. Combust. Flame., 7(1963)

26. K. Kuang, W. K. Chow, X. Ni, D. Yang. Fire Mater., 32(2008)

27. M. Krasnyansky. Fire Mater., 35(2011)

28. Z. Liu, A. K. Kim, D. Carpenter. Fire Safety J., 42(2007) 